\title{
Mulheres negras na contramão do afeto
}

\author{
Black Women wrong direction affection
}

Luana Franciele Miranda Souza ${ }^{1}$

\begin{abstract}
RESUMO
Este artigo analisa os impactos do entrecruzamento dos marcadores sociais de raça e gênero nas experiências afeto-subjetivas de mulheres negras do interior da Bahia, a partir das narrativas coletadas em entrevistas para a produção do livro-reportagem $\mathrm{Na}$ Contramão do Afeto: histórias e trajetórias afetivas de mulheres negras.
\end{abstract}

PALAVRAS-CHAVE: Mulheres Negras. Afetividade. Interseccionalidade.

\section{ABSTRACT}

This article analyzes the impacts of the intersection of social markers of race and gender on the affective-subjective experiences of black women from the interior of Bahia, based on the narratives collected in interviews for the production of the book-report In Wrong direction affection: stories and affective trajectories of black women.

KEYWORDS: Black Women. Affectivity. Intersectionality

$$
* * *
$$

\section{Introdução}

No fundo, todas se sentem em meio ao abismo dos sentimentos negados. Como se existir não fosse o bastante e o afeto fosse uma questão de sorte. Sentimento é consequência daquilo que semearam entre a gente, das representações sociais aos fluxos dos mercados afetivos e sexuais. Lançaram nossos corpos diante dos escombros da ausência de empatia e dos derrames de sangue. Diante do racismo que não nos deu o direito de estar bem, em companhia, com os nossos. $\mathrm{O}$ mesmo racismo que nos educou para sermos sós, quando nos fez entender que seríamos sempre as preteridas e violentadas diante do patriarcado branco que silencia nossas emoções.

-Epígrafe retirada do livro Na Contramão do Afeto

Em 2018, movida pela escassez de estudos que trouxessem para o centro das discussões intelectuais os impactos da interseç̧ão do racismo e

\footnotetext{
${ }^{1}$ Mestranda em Cultura e Sociedade, pelo Programa Multidisciplinar de Pós-Graduação em Cultura e Sociedade(UFBA). Graduada em Comunicação Social - Jornalismo (UFRB). E-mail:

luafmsouza@gmail.com.
} 
patriarcalismo nas trajetórias e experiências de mulheres negras, e pela ausência do debate racial em sala de aula durante a minha formação no curso de Comunicação Social-Jornalismo, iniciei uma pesquisa acompanhada pelo método da entrevista que resultou na produção do livro-reportagem $\mathrm{Na}$ Contramão do Afeto: histórias e trajetórias afetivas de mulheres negras, cujos resultados foram apresentados como trabalho de conclusão de curso. Durante esse período, estive preocupada em compreender de que forma as violências físicas e simbólicas produzidas pelos marcadores sociais (raça e gênero) têm incidido na construção da minha identidade e de demais mulheres negras, e na estruturação de laços familiares e comunitários que dão sentido às nossas existências.

Com o jornalismo, aprendi que para alcançar algumas respostas é preciso mergulhar fundo nas histórias das sujeitas que experienciaram as nuances daquilo que me proponho investigar. Nessa travessia, transformei a minha angústia disfarçada de curiosidade intelectual em uma grande reportagem que envolveu narrativas de cinco mulheres negras de idades e condições sociais diversas. Delas, duas são mulheres com as quais não havia uma aproximação anterior à pesquisa; outras duas, mulheres que faziam parte do meu círculo de pessoas conhecidas, porém, pouco sabia sobre as subjetividades e trajetórias emocionais/afetivas. A última mulher foi a que motivou, por meio das suas experiências de vida, os questionamentos que deram margem para iniciar os estudos sobre a afetividade das mulheres negras. Esta mulher sou eu. Com a minha tripla identidade de mulher, negra e candomblecista, aprendi sobre os silêncios que me obrigaram a conter as emoções, calar as dores e engolir o choro todas as vezes que algo me tocasse intimamente. Aprendi a seguir em frente sem falar muita coisa.

Esses aprendizados - um necessário e outro violento - , nortearam as questões que atravessaram e fundamentaram a produção deste trabalho. Por esse motivo, defendo a importância das narrativas de mulheres negras em primeira pessoa, por entender que as nossas vivências são fontes inesgotáveis 
de epistemes e se colocam como uma importante categoria política para a população negra.

A antropóloga Ana Cláudia Lemos Pacheco foi quem primeiro abriu caminhos para apurações acerca da construção das relações afetivas e solidão das mulheres negras na cidade de Salvador-Ba. Em Mulheres Negras: Afetividade e Solidão (2013) ela discorre sobre os aspectos da solidão que acomete uma grande porcentagem dessas mulheres em território baiano e, sobretudo, identifica a gritante influência dos fatores raça e gênero nas escolhas afetivas da população soteropolitana. Em outros termos, as experiências de emoções e afetos estariam acopladas aos padrões de relações dominantes do branco com o negro e do homem com a mulher.

Inspirado, também, pelos estudos de Pacheco, Na contramão do afeto narra tais experiências afetivas a partir das relações familiares e conjugais de mulheres negras da cidade de Cachoeira, situada no Recôncavo baiano. A escolha do território se deu, inicialmente, por se tratar da minha terra natal e devido à forte presença cultural e identitária da diáspora africana na constituição da população, como revelam pesquisas do Instituto Brasileiro de Geografia e Estatísticas e estudos sobre a formação populacional do Recôncavo baiano. Ainda de acordo com o IBGE, no senso de 2019, a cidade abrigava um pouco mais de 33 mil habitantes. Em 2010, a estimativa era de 32 mil habitantes, sendo 12.979 destes autodeclarados pretos e pardos. Esses dados ainda não foram atualizados.

Como supracitado, percebi ao longo da caminhada acadêmica e do meu processo de autoidentificação racial, a importância de pautar as mulheres negras e as interferências do racismo nas suas relações pessoais e afetivas, a fim de gerar reflexão acerca dos caminhos que elevam e reforçam a desigualdade de raça e gênero. Por esse motivo, me apropriei de um produto jornalístico não-periódico e literário porque comporta uma abordagem ampliada da temática, propondo uma linguagem leve e assertiva que contempla diversas camadas sociais e se estende para além da academia. A 
legitimidade e força do tema abordado encontram suporte nos relatos de cada entrevistada.

\section{Caminhos metodológicos}

O horizonte metodológico dessa pesquisa interagiu com o campo da sociologia das emoções quando trouxe a afetividade para o debate e se fragmentou, abrangendo outras áreas, como a antropologia dos estudos de gênero e raça, e os estudos culturais.

Deste modo, o trabalho adotou como técnica de pesquisa a entrevista aberta ou entrevista em profundidade ${ }^{2}$, na qual é possível analisar as histórias de vida e as experiências afetivas das mulheres negras com foco numa abordagem qualitativa. Enquanto técnica principal da Comunicação Social, Cremilda Medina (2011) compreende que a entrevista é um método que não atinge os limites proporcionados pela comunicação humana. Para haver humanização da entrevista é preciso que esta se aproxime do diálogo interativo, porque consegue promover o que ela vai chamar de fenômeno da identificação, onde o pesquisador e a fonte se interligam numa única vivência, possibilitando um maior aproveitamento de informações. O diálogo envolve a subjetividade e o imaginário das pessoas envolvidas.

Este método também é utilizado pela antropologia. Sua aplicação depende das escolas de pensamento e das abordagens teóricas. A biografia, por exemplo, como acentua Morin (1973), tem sido utilizada como método para abordar experiências de instituições, povos isolados e crenças, a partir das experiências individuais. Assim, as histórias de vida captam as diferenciações singulares das manifestações culturais. Dessa forma, utilizei essa ferramenta como narrativa biográfica, numa perspectiva de

\footnotetext{
$2 \mathrm{Na}$ comunicação Social a entrevista com profundidade busca, através de teorias e pressupostos, coletar respostas por meio da experiência subjetiva das fontes selecionadas.
} 
compreender como se interligam as experiências afetivas, políticas e socioculturais das entrevistadas, num contexto mais amplo.

A pesquisa se dividiu em duas partes. Na primeira, foi realizada uma análise bibliográfica a partir das teorias que fundamentam as questões de raça e gênero, bem como os estudos da afetividade e autoestima (CARNEIRO, 1995; FANON, 1983; GONZÁLES, 1983; hooks, 2000; PACHECO, 2013).

No último momento, foi aplicada a pesquisa exploratória, onde foram observadas e selecionadas as fontes para a realização da entrevista, com um questionário socioeconômico e perguntas que propiciaram o desenvolvimento da conversa-diálogo, a fim de construir o produto final.

\section{As intersecções de raça e gênero}

Com base nos estudos sobre gênero apresentados por escritoras como Simone de Beauvoir (1970), Adriana Piscitelli (2009) e Judith Butler (2003), compreendo, aqui, que o seu conceito foi formulado e difundido historicamente por pesquisadoras feministas e está relacionado aos aspectos socialmente construídos das diferenças sexuais. Em outras palavras, gênero reforça e propaga os ideais de macho e fêmea culturalmente definidos no contexto social, de acordo com as condições e lugares sociais que foram e ainda são naturalizados. À feminilidade, por exemplo, vinculou-se a ideologia do sexo frágil, dos aspectos afetivos, da delicadeza, dos serviços domésticos, da maternidade; enquanto ao ser masculino, constituiu-se o ideal da virilidade, do dominador. A naturalização dessa cultura que define o que é ser homem e mulher legitimou, ao longo do seu desenvolvimento, uma desigualdade de gênero, evidenciado nas relações onde as mulheres protagonizam papéis subordinados.

Essa definição de gênero demarcou, dentro do movimento feminista, a ideia de igualdade entre as mulheres descartando as possibilidades de percepção das diferenças que, logicamente, existiam entre elas. As diferenças de raça e condição social, por exemplo. Este problema da negação das 
especificidades femininas foi destacado por Sueli Carneiro, que em seguida reivindicou a urgência do enegrecimento do feminismo.

Ao politizar as desigualdades de gênero, o feminismo transforma as mulheres em novos sujeitos políticos. Essa condição faz com que esses sujeitos assumam, a partir do lugar em que estão inseridos, diversos olhares que desencadeiam processos particulares subjacentes na luta de cada grupo particular. Ou seja, grupos de mulheres indígenas e grupos de mulheres negras, por exemplo, possuem demandas específicas que, essencialmente, não podem ser tratadas, exclusivamente, sob a rubrica da questão de gênero se esta não levar em conta as especificidades que definem o ser mulher neste e naquele caso. Essas óticas particulares vêm exigindo, paulatinamente, práticas igualmente diversas que ampliem a concepção e o protagonismo feminista na sociedade brasileira, salvaguardando as especificidades. Isso é o que determina o fato de o combate ao racismo ser uma prioridade política para as mulheres negras, assertiva já enfatizada por Lélia Gonzalez, "a tomada de consciência da opressão ocorre, antes de tudo, pelo racial" (CARNEIRO, 2013, p. 119)

Assim como Sueli destacou a invisibilização das especificidades das experiências de mulheres negras nas pautas feministas, Lélia Gonzáles (1988), por sua vez, reforçou as práticas de subordinação e subumanização da existência feminina negra na formação sócio-cultural do povo brasileiro e, inclusive, dentro do movimento negro.

Ao apontar para as problemáticas que sentenciaram mulheres negras às diversas formas de violências físicas e simbólicas, Lélia atentava-nos para a necessidade de pensar as desigualdades pelo viés da interseccionalidade, ou seja, refletir essas questões que afetam principalmente mulheres negras, a partir das opressões entrecruzadas projetadas pelas articulações em torno dos marcadores raça e gênero. A ativista Luiza Bairros (1988) também criticou a conduta embranquecida do movimento feminista, afirmando que a discussão sobre o corpo e a sexualidade expressavam a contradição com relação à realidade concreta das mulheres negras e pobres. 
As emoções e afetos das mulheres negras foram, historicamente, suprimidos pelas opressões e explorações que distorceram a nossa capacidade de demonstrar e sentir amor. Sobre isso, bell hooks discorre

Numa sociedade onde prevalece a supremacia dos brancos, a vida dos negros é permeada por questões políticas que explicam a interiorização do racismo de um sentimento de inferioridade. Esses sistemas de dominação são mais eficazes quando alteram nossa habilidade de querer e amar. Nós negros temos sido profundamente feridos, como a gente diz, "feridos até o coração", e essa ferida emocional que carregamos afeta a nossa capacidade de sentir e consequentemente, de amar. Somos um povo ferido. Feridos naquele lugar que poderia conhecer o amor, que estaria amando (hooks, 2000).

A afirmação de bell hooks traduz, em tempos presentes, o que Sueli Carneiro (2019) observou acerca da formação da população brasileira resultante do estupro colonial que sentenciou mulheres negras e indígenas à brutalidade do patriarcalismo branco. Esses caminhos, embora pontuados por intelectuais negras de locus enunciativos diferentes - sendo hooks uma escritora afro-estadunidense e Carneiro afro-brasileira - nos conduzem ao contexto em que essas "fragilidades" do sentir foram construídas e potencializadas de forma perversa.

Trata-se de refletirmos sobre o vergonhoso período escravagista, no qual mulheres negras eram obrigadas a virem seus filhos e maridos chicoteados até a morte pelas mãos dos feitores que sequer ligavam para a sua dor. No mesmo cenário, viam seus bebês serem vendidos como moeda de troca; assistiam a desestruturação violenta das suas família e tinham o direito de sofrer e viver o luto negados pela maldade humana. Ainda assim, seguiam a rota sem sucumbir.

Diante dessas circunstâncias e do cruel distanciamento daquilo que hoje compreendemos como amor e afeto, essas mulheres tiveram suas emoções subtraídas e, consequentemente, entendiam as dificuldades de 
experimentar e vivenciar qualquer construção amorosa de uma relação, seja ela familiar ou íntima. Havia, naquele contexto, uma negligência intencional com o sentimento e a saúde emocional de mulheres negras.

Nos dias atuais, essas experiências foram ressignificadas à medida em que ocorriam os avanços civilizatórios instituídos pelo movimento de mulheres negras dissidentes que impuseram suas especificidades nas pautas feministas que, em outrora, corroboraram com o apagamento e silenciamento das existências e vozes femininas negras.

Entretanto, as práticas de invisibilização da experiência de sujeitas negras, bem como as reconfigurações das maneiras de oprimir e subjugar as nossas potencialidades, permanecem protegidas pela atuação do racismo e patriarcalismo que seguem unificados fazendo a manutenção dos seus sistemas excludentes, perversos e estruturantes.

Perde-se o regime escravocrata, onde podia-se, amparado pela legislação, subumanizar corpos negros e, em contrapartida, cria-se novas políticas de extermínio da raça, que atuam física-simbólica-emocionalmente nas vidas das sujeitas e sujeitos racializados. A necropolítica, como definiu Achille Mbembe (2010), parte da promoção do genocídio da população negra, configurando-se, principalmente, pelo extermínio do homem negro. Seja por meio de ações mediadas pelo Estado e suas instituições, como o encarceramento em massa; seja por meio das políticas de guerra às drogas que seguem condenando inúmeros jovens negros que habitam as margens da sociedade.

[...]mais do que o pensamento de classe (a ideologia que define história como uma luta econômica de classes), a raça foi a sombra sempre presente sobre o pensamento e a prática das políticas do Ocidente, especialmente quando se trata de imaginar a desumanidade de povos estrangeiros - ou dominá-los (MBEMBE, 2010, p. 128). 
O intelectual camaronês, Achille Mbembe, traduz, a partir da perspectiva de biopoder apresentada pelo filósofo francês Michel Foucault, a afirmativa de que a política de raça está intimamente relacionada à política de morte. Isto explica a importância dos movimentos populares contra o genocídio da população negra protagonizados, majoritariamente por mulheres negras.

A compreensão desse contexto político e dos interesses que há por trás do apagamento de um grupo racializado, justifica esse levante necessário que tem questionado a atuação da polícia, sob a ordem do Estado, nas periferias e espaços demarcados pela negritude.

Entretanto, o que interessa nessas linhas é olhar para quem está por trás desse cenário brutal. São as sujeitas esquecidas pelos defensores do dito "bandido bom é bandido morto". Elas são as esposas negras, as mães pretas que continuam chorando a morte cruel de seus filhos e assistindo a desestruturação da sua família, sem nenhum amparo e sem o direito de viver o luto, porque tem um outro "guri" que ainda está vivo e ela precisa buscar o alimento para saciar a sua fome. Precisa tentar, com a pouca força e dinheiro que tem, desviá-lo desse destino perverso.

Essas mulheres - que no período da escravização atuavam como amade-leite; mães pretas que não podiam cuidar dos seus filhos, mas eram obrigadas a amamentar os filhos das sinhás - hoje atuam como babás, domésticas, nas mesmas profissões de outrora. Não quero, com isso, reduzir o valor das profissões, mas restituir passos que seguem fincados na mesma estrutura em que começou. As mulheres negras, da periferia, continuam ocupando cargos de menores salários e valorização social. Continuam nas profissões de domesticação e vendo seus filhos morrerem enquanto cuidam dos filhos dos patrões.

Motivada por essas observações, trago Beatriz Nascimento - a mulher Atlântica, intelectual negra que teve, durante décadas, as suas produções invisibilizadas - quando ela afirma que o racismo é um "emaranhado de sutilezas" que se multiplica como se tivesse sete vidas. São essas sutilezas que 
permitem que as mesmas condições sociais experienciadas no passado sejam reconfiguradas no presente e mantenham, mesmo que com os avanços, as mulheres negras na base da pirâmide social.

A mulher negra na sua luta diária durante e após à Escravidão no Brasil, foi contemplada como mão- de obra, na maioria das vezes não qualificada. Num país em que só nas últimas décadas desse século, o trabalho passou a ter significado dignificante, o que não acontecia antes, devido ao estigma da escravatura, reproduz-se na mulher negra "um destino histórico". É ela quem desempenha, em sua maioria, os serviços domésticos, os serviços em empresas públicas e privadas recompensadas por baixíssimas remunerações. São de fato empregos onde as relações de trabalho avocam as mesmas da Escravocracia (NASCIMENTO, 1990).

Nesse sentido, se enxergamos uma transformação na sociedade brasileira nas últimas décadas no que tange as mulheres e, ainda assim, assumimos a crença de que todas elas foram contempladas com tais mudanças da mesma maneira e proporcionalidade, estamos mais uma vez esquecendo que a categoria mulher não deve ser entendida como universal. Ouso trazer essa afirmativa porque como já fora supracitado, algumas formas de violências são heranças coloniais e seguem gerando danos, principalmente na emocionalidade de mulheres negras.

Torna-se difícil não reconhecer como os discursos de ideologias raciais e de gênero são estruturantes e ordenam um conjunto de práticas corporais racializadas vividas pelo gênero, na sexualidade, no trabalho, na afetividade e em outros lugares sociais "destinados" às mulheres negras na Bahia e no Brasil (PACHECO, 2013, p.24).

Essa reconfiguração do cenário de opressões e inibições da evolução e prosperidade das mulheres negras em todas as esferas das suas vidas impactam, especialmente na estruturação da sua emoção, dos seus afetos e 
relações. Assim, a partir dessa rápida contextualização, parto para as reflexões acerca dos símbolos e significados das interferências do racismo e suas intersecções presentes nas narrativas de mulheres negras colhidas durante a produção do livro-reportagem Na Contramão do Afeto: histórias e trajetórias afetivas de mulheres negras.

Quando iniciei as entrevistas para o livro-reportagem, questionei-me inúmeras vezes sobre como preservar os nomes das entrevistadas, mantendo uma conexão relevante com a profundidade das histórias narradas. Assim, tive a ideia de substituir seus nomes de batismo, por nomes de personagens femininas que constituem a religiosidade afro-diaspórica das tradições congoangola. Desse modo, trouxe Ndandalunda (senhora das águas doces, do gestar afeto e das emoções que perpassam todas as trajetórias de dores e resistência), Kaitumba (dona da inconstância das ondas dos mares, do amor e sensibilidade), Matamba (senhora dos raios, força e justiça) e Zumbaranda (a mais velha, aquela que traz vida para o centro do mundo e a devolve para a continuação da ancestralidade). A escolha foi negociada com as quatro entrevistadas e determinada de acordo as especificidades de cada uma delas.

Isto posto, retomo a discussão sobre a afetividade dessas mulheres.

\section{Mulheres negras e Afetividade}

\subsection{Das violências físicas e simbólicas}

“Eu apanhava muito. Era horrível!" Esta frase foi proferida por uma das entrevistadas, Matamba, mulher negra, 54 anos, trabalhadora doméstica. Em sua narrativa, a violência física e emocional atravessou todos os seus relacionamentos afetivos. No primeiro casamento, teve quatro filhos de um homem que a espancava na frente das crianças e as deixavam sem ter o que comer. Roubava o dinheiro que a esposa conseguiu lavando trouxas de roupas e cozinhando para os patrões, para se divertir com amantes. A morte precoce deste homem, consequente de um grave problema de saúde, representou para 
essa mulher a sua libertação, haja vista que por toda vida entendeu o casamento como uma prioridade, uma oportunidade de não ficar sozinha, por se entender preterida por outros homens, motivo que a manteve presa por quase dez anos em um relacionamento abusivo. Viveu outros relacionamentos com o mesmo efeito das violências vividas no anterior.

$\mathrm{O}$ medo do preterimento e da solidão sentenciam inúmeras mulheres negras à relacionamentos fadados ao fracasso. Este medo, fruto das opressões produzidas pelo entrecruzamento de raça e gênero que colocou barreiras na construção da autoestima dessas mulheres, disseminou as violências que agridem profundamente as suas existências.

Emerge daí a cruel percepção desenhada e impetrada pelo patriarcalismo nos processos de socialização, de que o corpo feminino negro deve ser objetificado e domado como uma coisa qualquer; e esse entendimento tem motivado homens, sejam negros ou brancos, a tratarem essas sujeitas como subumanas cujo os sentimentos e emoções são desconsiderados e não possuem valor algum. Ao pensar essa postura de brutalidade protagonizada por homens negros, trago uma reflexão de bell hooks acerca da estruturação das famílias negras.

Imagino que, após o término da escravidão, muitos negros estivessem ansiosos para experimentar relações de intimidade, compromisso e paixão, fora dos limites antes estabelecidos. Mas é também possível que muitos estivessem despreparados para praticar a arte de amar. Essa talvez seja a razão pela qual muitos negros estabeleceram relações familiares espelhadas na brutalidade que conheceram na época da escravidão. Seguindo o mesmo modelo hierárquico, criaram espaços domésticos onde conflitos de poder levavam homens a espancarem mulheres e os adultos a baterem nas crianças como que para provar seu controle e dominação (hooks, 2000).

Embora pareça que bell hooks busca uma justificativa para a compreensão da atitude violenta vinda de homens negros contra suas 
companheiras e família, o que observo é que ela propõe uma reflexão sobre as condutas Ocidentais que se baseiam nas relações dominantes estabelecidas pelos marcadores sociais de raça e gênero, e que são, consequentemente, reproduzidas por aqueles que conviveram em berços constituídos pela violência. Um exemplo disso reflete no que Ana Cláudia Pacheco (2013) traz, ao analisar os estudos de Florestan Fernandes sobre a nova ordem social de competitividade que desestabilizou negras e negros em diferentes aspectos da vida.

Assim, o comportamento sexual e afetivo das pessoas de cor seria fruto de uma herança cultural escravista, que foi se desestruturando no processo de escravização da mão de obra e com o advento da sociedade industrial moderna (PACHECO, 2013; p. 30).

Entrentanto, apesar da importância dessa análise e da total concordância sobre a necessidade de ampliar o debate sobre as formas atuais de constituição das relações que envolvem sujeitas e sujeitos negros, considero que este processo, na prática, demanda um trabalho de (re) educação psíquica, emocional e, sobretudo, o desmonte de um sistema que ainda tem todos os aparatos para se manter firme e no topo do poder, da dominação.

Isto porque as mulheres negras continuam sendo as que mais sofrem nesse contexto, pois são consideradas "presas" fáceis desde o trânsito atlântico onde seus ancestrais foram forçados a fincarem os pés em terras ocidentais. A subumanização do seu corpo e a desvalorização da sua emoção e afeto demarcam a coisificação do seu existir. E essa coisificação é incorporada na sua subjetividade que internaliza e se adapta ao não lugar da suas emoções, fazendo-lhes acreditar que o pouco ou nenhum amor na sua vida é fruto do seu merecimento.

(...) estamos diante de um continuum histórico que, passando de mucama à doméstica, mantém a tradição de uso e abuso sexual da mulher negra, 
entendendo-se aqui por mulheres negras as diferentes matizes com que as pessoas se autoclassificam... (CARNEIRO, 2019, p.165)

Nos dias atuais, a gente aprende a silenciar nossas emoções ainda na infância, quando os nossos pais nos obrigam a "engolir o choro" para não transparecer o que sentimos no interior, o que nos incomoda e nos afeta. Muitas vezes essa prática não é entendida como uma forma de silenciar nossas dores, mas é reproduzida e internalizada por nós durante toda a vida. É uma forma de violência simbólica que perpassa por diversas esferas da nossa existência. Afeta nossa mente, nosso coração e, em algumas situações, a nossa pele, como o caso da minha entrevistada.

Conhecer as raízes dessas opressões tem nos ajudado a criar estratégias para driblar essas ações que nos tomam como vítimas e dilacera as bases da nossa emocionalidade. Guardamos muitas dores e o acúmulo delas nos levam a uma vida infeliz e injusta, já que a nossa história é marcada por apagamentos, privações, luto, agressões, medo e, sobretudo, solidão.

Kaitumba, de apenas 21 anos, relata as agressões verbais protagonizadas por seu pai, com quem morou assim que sua mãe faleceu precocemente de um câncer. Foi vítima de estupro cometido por um excompanheiro, quando tinha 15 anos. Tem uma trajetória de vida marcada pela experiência de sucessivas opressões e o medo de ser mais uma mulher negra nas estatísticas.

Para além das hostilidades, narra, também, os problemas de autoestima que, por muitos anos, lhe impediram de se sentir bem com a própria pele e os traços que indicam a sua negritude. Argumenta que, possivelmente, a sua identidade negra tivesse sido o motivo para tantos problemas na vida.

Nota-se neste segundo caso, também, a reprodução de práticas cruéis características do regime de escravização. O estupro, o machismo, a reprodução das agressões físicas do pai, a negação da própria identidade, por 
entender que ser mulher negra, num país como o nosso, é estar a mercê de toda brutalidade promovida pelas opressões entrecruzadas.

Isto posto, retomo a discussão de Sueli Carneiro sobre o estupro colonial, porque "está na origem de todas as construções sobre a identidade nacional e construções hierárquicas de gênero e raça presentes em nossa sociedade" (CARNEIRO, 2002, p.169). Trata-se de conectar aspectos do racismo e sexismo do passado às relações permeadas pelo patriarcalismo, racismo e sexismo nos dias atuais, reafirmando o seu caráter estruturante.

Por outro lado, embora eu tenha enfatizado os processos históricos e simbólicos que interferem na constituição emocional e afetiva de mulheres negras, quiçá, deixando parecer que todas as nossas conquistas até hoje foram insignificantes, é importante ressaltar que as vitórias foram e são tão valiosas não só pelos esforços colocados nas lutas de resistência contra esse sistema estrutural e estruturante, mas também pelos significados que esses movimentos deram ao nosso presente.

Cabe estabelecer, nessas linhas, a importância das ações desempenhadas por mulheres negras conscientes desse cenário de repressão e opressão, que além de marcharem contra nossos algozes, abriram os caminhos para que possamos e tenhamos o direito de exercer o controle sobre nossas vidas e emoções. Bem como as mulheres negras que demarcam as margens, que habitam as periferias e, mesmo sem acesso aos conhecimentos científicos e teóricos, desempenham um trabalho ancestral de cuidado e maternagem, seja ela biológica ou não, dentro da sua comunidade.

Mulheres essas que carregam, além da negritude, a força para combater à sua forma as violências domésticas que corriqueiramente lhe acomete e o feminicídio que lhes cercam. Mulheres que estiveram e ainda permanecem na linha de frente nas avenidas do racismo e sexismo, e seguem sendo exemplos para inúmeras sujeitas negras que buscam sua autonomia, visibilidade e ocupação em espaços de poder. Como bem nos ensina bell hooks (2019), mulheres que ergueram a voz. 


\subsection{Das resistências e desafetos}

Ao trazer essa força feminina negra que tem recriado maneiras de ser e estar no mundo em insubordinação a ordem patriarcal e racista que ainda nos cerca, trago a existência de Ndandaluna, uma mulher negra de 54 anos que se viu nas avenidas das opressões ainda na juventude. Engajada nas causas raciais, conta que decidiu torna-se mãe solo por entender que a maternidade é um processo no qual, muitas vezes, mulheres negras encontram-se sozinhas. A sua insubimissão aos parceiros, bem como os problemas afetivos vividos com a mãe, uma mulher branca que casou-se com um homem negro e, ainda assim, não aceitava a negritude de seus filhos, fezlhe buscar a prosperidade profissional e autonomia.

Ao contrário de Matamba, uma mulher que nasceu em um berço familiar desestruturado, não teve estudos e, consequentemente, não possui um conhecimento mais acadêmico sobre as questões raciais e de gênero, Ndandalunda é professora, graduada em Psicologia, Sociologia e Filosofia, bagagens suficientes para uma trajetória emancipatória e para uma compreensão mais crítica acerca da sua realidade e de tantas outras mulheres.

Para ela a solidão é o preço a ser pago pela insubordinação às ferramentas de controle exercidas pelo imaginário branco sobre a negritude feminina. E esta solidão se desenha nas relações com a família que a considera "diferente e questionadora demais", pela forte tendência em fazer observações frente às atitudes e falas racistas e machistas de seus irmãos.

Audre Lorde traduziu muito bem essa sensação angustiante de se sentir isolada do mundo e da nossa família por termos subido um degrau a mais em termos de conhecimento e aprendizado, em relação aos nossos parentes. Ela dizia que enquanto "os patriarcas brancos nos disseram: 'Penso, logo existo’. A mãe negra dentro de cada uma de nós - a poeta - sussurra em nossos sonhos: 'Sinto, logo posso ser livre”'(LORDE, 2019, p.26). 
A liberdade é, para a mulher negra, a justificativa para uma luta cotidiana, porque ainda não foi possível experimentarmos essa sensação que pulsa dentro de nós. O estado do ser livre, quando anotado na caderneta da vida, tem um custo muito alto e muitas que ousaram pagar o preço ou morreram sem conseguir experimentar ou seguem lutando para que antes da partida alcancem o direito de sentir. Como bem pontuou Sueli Carneiro, "as mulheres da minha geração compreenderam o sentido da palavra liberdade e igualdade em função da sede que a ausência de liberdade e igualdade nos provocou” (2019, p. 108). Ou seja, para as nossas ancestrais, aquelas que pisaram a terra antes de nós, a liberdade tem um valor supremo e lhes fora negada. Cabe a nós, agora, continuar resistindo para libertar a nossa comunidade que segue aprisionada em todas as esferas da vida.

Assim, para colorir ainda mais essa percepção sobre liberdade e solidão, revisito os passos de Beatriz Nascimento que implementa em sua narrativa a experiência sobre ser uma mulher negra em ascensão social.

Quanto mais a mulher negra se especializa profissionalmente numa sociedade desse tipo, mais ela é levada a individualizar- se. Sua rede de relações também se especializa. Sua construção psíquica, forjada no embate entre a sua individualidade e a pressão da discriminação racial, muitas vezes surge o impedimento à atração do outro, na medida em que este, habituado aos padrões formais de relação dual, teme a potência dessa mulher . Também ela, por sua vez, acaba por rejeitar esses outros, homens, masculinos, machos. Já não aceitará uma proposta de dominação unilateral. (NASCIMENTO, 1990)

Nesse contexto, trago para o centro da discussão a trajetória de Zumbaranda, uma mulher de setenta e poucos anos que vive sozinha por escolha. Ela não estudou e narra que a sua avó paterna, por quem foi criada, era uma ex-escravizada e foi com a sua experiência de vida que aprendeu sobre liberdade e autonomia. Casou duas vezes e nos dois relacionamentos sofreu com a traição e aproveitamento de seus parceiros que lhe roubam o 
pouco que ganhava como lavadeira, para se divertir e beber. Decidiu, por conta própria, dar um basta nos dois relacionamentos. Mas, segundo ela, nunca tomou uma decisão sozinha. Sua vida é conduzida pelas forças e proteção dos Orixás, divindades do Candomblé, religião que norteia toda a sua existência e ancestralidade.

A companhia mítica das entidades tem sido grande aliada nos dias que passam e reduzem ainda mais a sua estadia no Aiyê (terra). Alguns vizinhos se responsabilizaram em visitá-la diariamente, para saber se está bem e precisando de alguma ajuda. Vive numa casa muito simples, onde paga o aluguel com o pouco trocado da sua aposentaria. Com o que sobra, compra comida. A solidão, para Zumbaranda, é um misto de complexidades. Ora, parece maravilhoso, não tem quem lhe perturbe; Ora, é como uma vendaval que vem e dilacera tudo o que há. Neste caso, abre feridas profundas que muitas vezes não cicatrizam.

Destarte, apreendo das experiências dessas mulheres que compuseram o meu primeiro trabalho acadêmico, o livro-reportagem - e têm guiado os demais; unindo à minha trajetória de mulher negra que carrega em si, também, feridas que por muitos anos chegaram a "doer na alma", como nos ditos populares - que as nossas emoções carregam a bagagem dos contextos sociais em que estivemos e ainda estamos inseridas por longas décadas.

Por vivermos em uma sociedade que percebe os efeitos do racismo e sexismo nas nossas vidas, mas segue com as vendas nos olhos e, ao invés de buscar a solução prefere nos intitular de "mulheres guerreiras", romantizando as nossas lutas cotidianas, estamos caminhando na contramão do afeto. Enquanto nossos filhos, irmãos e companheiros continuarem na mira da morte do racismo, continuaremos na contramão do afeto. $\mathrm{E}$ enquanto os nossos corpos forem enxergados como objeto, e continuarmos norteadas pela necessidade de resistir, seguiremos na contramão.

As nossas emoções caminham com as nossas lutas e pelas trincheiras do resistir tem mais dores que estabilidade emocional. A gente segue cuidando dos nossos, mas quem vai cuidar da gente? 


\section{Encerrando um ciclo}

A partir de análise das narrativas coletadas para a grande reportagem, pode-se inferir que o racismo em intersecção com os aspectos heteronormativos e patriarcais entorno do gênero impactam as relações de afeto constituídas por mulheres negras. Tal interferência tem suas raízes de atuação ancoradas no período escravagista, quando mulheres e homens negros foram arrastado de suas terras, onde viviam um modo de ser, estar e sentir norteadas pelas tradições de afeto e estabilidade emocional apreendidas nas relações com os mais velhos e perpassadas por gerações. Longe de suas famílias e de sua tradição socio-cultural - porque afeto e emoção são constituídos de formas divergentes em diferentes territórios tiveram suas trajetórias afetivas reconfiguradas por povos que sequer lhes enxergavam como humanos.

A adaptação a este novo mundo gestou mulheres profundamente "feridas" fisicamente e emocionalmente, pois, como fora mencionados linhas acima, todas as experiências vivenciadas em tempos de aprisionamento existencial, tiveram espaços para se ressignificarem nos dias atuais e continuarem agindo como uma praga que dilacera qualquer possibilidade de ancorar boas sensações, bons afetos.

Ainda assim, embora trilhando por alguns caminhos tortuosos, mulheres negras, mesmo que na contramão do afeto, dão conta de erguer a voz e denunciar o caos que tanto nos aprisionam. Essas narrativas vêm colocando cor ao que até pouco tempo atrás só era visto em preto e branco, isso quando era enxergado. O rompimento com a máscara do silenciamento, como bem destaca Grada Kilomba (2019), é o que nos mantém ativas, transformando as margens em espaços de produtividade e resistência.

Mesmo feridas na alma, somos capazes de enxergar possibilidades nas ausências que tanto nos aflinge. Mesmo ocupando os espaços de poder, ainda somos vistas como pequenas selvagens que não deveriam estar ali. Como mulheres que não devem ser amadas, que não devem viver em paz, em 
liberdade. E ao falarmos sobre isso, ao erguemos a voz, confrontamos não só o racismo e suas intersecções, mas toda uma história que tentou nos confinar nos guetos e na marginalização, impedindo-nos de (re) existir.

Portanto, as nossas trajetórias, quando contadas por nós mesmas, tendem a invocar inúmeros fatores que nos norteiam e transformam-se em ferramentas que dão conta de denunciar todas as violências que foram e ainda são praticadas contra nossa existência. Os nossos corpos são territórios que abrigam as nossas emoções, a força ancestral, bem como a nossa identidade, a nossa história e a nossa capacidade de seguir resistindo e gestando emoções por todo trajeto.

\section{Referências}

BAIRROS, Luíza. Nossos feminismos revisitados. Revista Estudos Feministas, V.3, n 2 , IFCS / UFRJ, R.J, 1995.

Mulher negra: o reforço da subordinação. In: João José Reis (Org.).

Escravidão e invenção da liberdade, Estudos sobre o negro no Brasil, São Paulo: Brasiliense, 1988.

BEAUVOIR, Simone de. O segundo sexo: fatos e mitos. São Paulo: Difusão Europeia do Livro, 1970.

BUTLER, Judith. Problemas de gênero: feminismo e subversão da identidade. Rio de Janeiro: Editora Civilização Brasileira.

CARNEIRO, Sueli. Gênero, Raça e Ascensão Social, Estudos Feministas, V-3, nº 02, 1995.

. Mulheres em Movimento. Estudos Avançados 17 (49) 2003.

. Identidade Feminina. In. Cadernos Geledés. №4, 1993.

. Enegrecer o feminismo: a situação da mulher negra na América Latina a partir de uma perspectiva de gênero. In: ASHOKA Empreendimentos Sociais; TAKANO Cidadania (Org.). Racismos contemporâneos. Rio de janeiro; Takano, 2003.

Escritos de uma vida. São Paulo: Pólen Livros, 2019.

FANON, Franz. Pele Negra, Máscaras Brancas, tradução de Maria Adriana da Silva Caldas, Fator, Rio de Janeiro, 1983. 
GONZALEZ, Lélia. Racismo e sexismo na cultura brasileira. In: SILVA, L. A. et al. Movimentos sociais urbanos, minorias e outros estudos. Ciências Sociais Hoje, Brasília, ANPOCS n. 2, p. 223-244, 1983.

hooks, bell. Vivendo de amor. In: Werneck, J. O livro da saúde das mulheres negras: nossos passos vêm de longe. Rio de Janeiro: Pallas: Criola, 2000, p.197.

. Erguer a voz: pensar como feminista, pensar como negra. São Paulo: Editora Elefante, 2019.

Olhares negros: raça e representação. São Paulo: Elefante, 2019.

KILOMBA, Grada. Memórias da Plantação: episódios do racismo cotidiano. Rio de Janeiro: Editora Crobogó, 2019.

LORDE, Audre. Irmãs Outsider: ensaios e conferências. Belo Horizonte: Autêntica Editora, 2019.

MBEMBE, Achille. As Formas Africanas de Auto-Inscrição. In Estudos AfroAsiáticos, Ano 23, no 1, 2001, pp.171-209. Disponível em: $<$ http://www.scielo.br/pdf/eaa/v23n1/a07v23n1.pdf >

MEDINA, Cremilda. Entrevista: O diálogo possivel. 1.ed. São Paulo: Ática, 2011.

MORIN, Edgar. A entrevista nas Ciências Sociais, na rádio e na televisão. In:

MOLES, Abraham A. et alii. Linguagem da Cultura de Massa. Petrópolis, Vozes, 1973.

NASCIMENTO, Beatriz. A Mulher Negra e o amor. In: Jornal Maioria Falante, ${ }^{\circ}$ 17,Fev - março, 1990, p. 3.

PACHECO, Ana Cláudia Lemos. Raça, gênero e escolhas afetivas: uma abordagem preliminar sobre solidão entre mulheres negras em Salvador, Bahia. Temáticas, Campinas, 11(21/22): 11-48, jan./dez.2003. pp.11-48.

"Branca para casar, mulata para "F" e negra para trabalhar": Escolhas afetivas e significados de solidão entre mulheres negras em Salvador, Bahia. 2008. 317 p. Tese (Doutorado em Ciências Sociais) - Instituto de Filosofia e Ciências Humanas, Universidade Estadual de Campinas, São Paulo, 2008.

.Mulher negra: afetividade e solidão. Edufba, Salvador, 2013.

PISCITELLI, Adriana. Gênero: a história de um conceito. In: BUARQUE DE ALMEIDA, H.; SZWAKO, J. (Org.). Diferenças, igualdade. São Paulo: Berlendis\&Vertecchia, 2009. p. 116-148.

Recebido em julho 2020. Aprovado em novembro 2020. 